UCRL-ID- 122841

\title{
Cost Analysis Guidelines
}

R. Scott Strait

\section{RECEIVED \\ APR 181996 \\ OSTI}

January 10, 1996

This is an informal report intended primarily for internal or limited external distribution. The opinions and conclusions stated are those of the author and may or may not be those of the Laboratory.

Work performed under the auspices of the U.S. Department of Energy by the Lawrence Livermore National Laboratory under Contract W-7405-Eng-48.

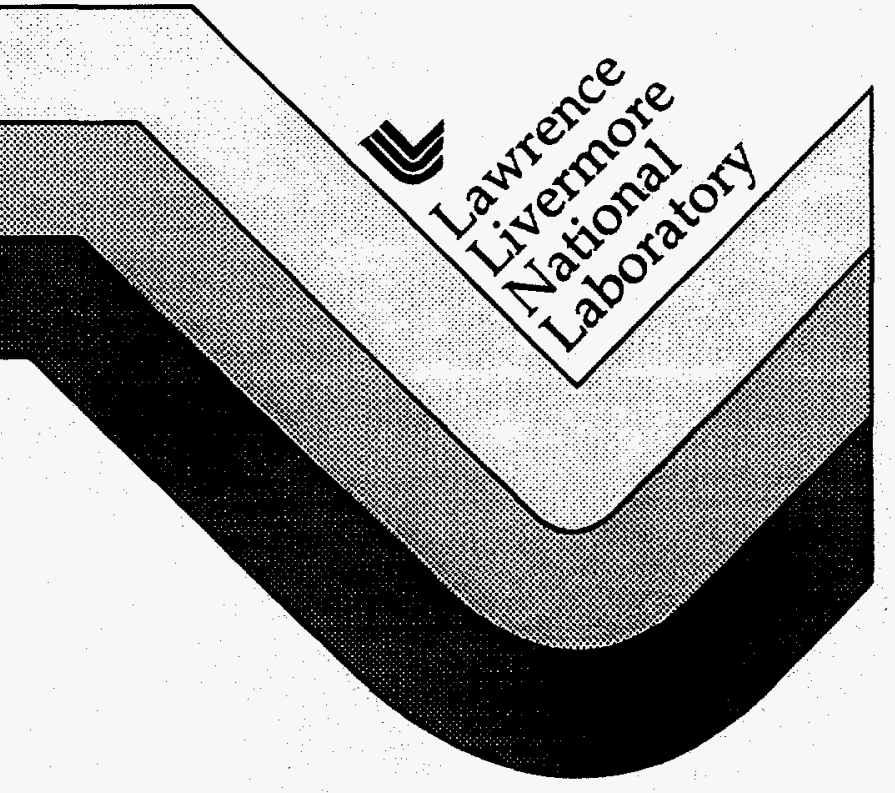




\section{DISCLAIMER}

This document was prepared as an account of work sponsored by an agency of the United States Government. Neither the United States Government nor the University of California nor any of their employees, makes any warranty, express or implied, or assumes any legal liability or responsibility for the accuracy, completeness, or usefulness of any information, apparatus, product, or process disclosed, or represents that its use would not infringe privately owned rights. Reference herein to any specific commercial product, process, or service by trade name, trademark, manufacturer, or otherwise, does not necessarily constitute or imply its endorsement, recommendation, or favoring by the United States Government or the University of California. The views and opinions of authors expressed herein do not necessarily state or reflect those of the United States Government or the University of California, and shall not be used for advertising or product endorsement purposes.

This report has been reproduced directly from the best available copy.

Available to DOE and DOE contractors from the Office of Scientific and Technical Information P.O. Box 62, Oak Ridge, IN 37831

Prices available from (615) 576-8401, FTS 626-8401

Available to the public from the National Technical Information Service

U.S. Department of Commerce 5285 Port Royal Rd. Springfield, VA 22161 


\section{Cost Analysis Guidelines}

\section{Introduction}

The first phase of the Depleted Uranium Hexafluoride Management Program (Program)management strategy selection-consists of several program elements: Technology Assessment, Engineering Analysis, Cost Analysis, and preparation of an Environmental Impact Statement (EIS). Cost Analysis will estimate the life-cycle costs associated with each of the long-term management strategy alternatives for depleted uranium hexafluoride (UF6). The scope of Cost Analysis will include all major expenditures, from the planning and design stages through decontamination and decommissioning. The costs will be estimated at a scoping or preconceptual design level and are intended to assist decision makers in comparing alternatives for further consideration. They will not be absolute costs or bid-document costs.

The purpose of the Cost Analysis Guidelines is to establish a consistent approach to analyzing of cost alternatives for managing Department of Energy's (DOE's) stocks of depleted uranium hexafluoride (DUF6). The component modules that make up the DUF6 management program differ substantially in operational maintenance, process-options, requirements for $R \& D$, equipment, facilities, regulatory compliance, (O\&M), and operations risk. To facilitate a consistent and equitable comparison of costs, the guidelines offer common definitions, assumptions or basis, and limitations integrated with a standard approach to the analysis.

Further, the goal is to estimate total net life-cycle costs and display them in a way that gives DOE the capability to evaluate a variety of overall DUF6 management strategies, including commercial potential. The cost estimates reflect the preconceptual level of the designs. They will be appropriate for distinguishing among management strategies.

The Guidelines address the total estimated life-cycle costs of the component modules. The modules, or building blocks from which a alternative management strategies can be built and which are described in detail in the Work Breakdown Structure Report, include

- conversion

- recycle/reuse

- storage

- permanent disposal

- current DUF6 management Plan and cylinder refurbishment

- transportation

These major modules, shown in Fig. 1, represent the basic building blocks for constructing a complete management strategy alternative and its primary capital and operating costs. Figure 2, Cost Analysis Guidelines Scope, shows each phase of the Cost Analysis Project. Other life-cycle cost factors that contribute to and affect the primary costs are also shown in Fig. 2. These include

- $\quad \mathrm{R} \& \mathrm{D}$ costs

- contingency for cost uncertainty 
- permits, licensing, and environmental documentation

- market survey, sales revenue, and product/waste mix

- production rate

- site selection

- process royalty costs

- ownership/operation alternatives.

- business risk

- D \& D costs

As can be seen from the list of cost modules and categories, the scope includes all major expenditures over the life of the project from preoperational through decontamination and decommissioning activities. 


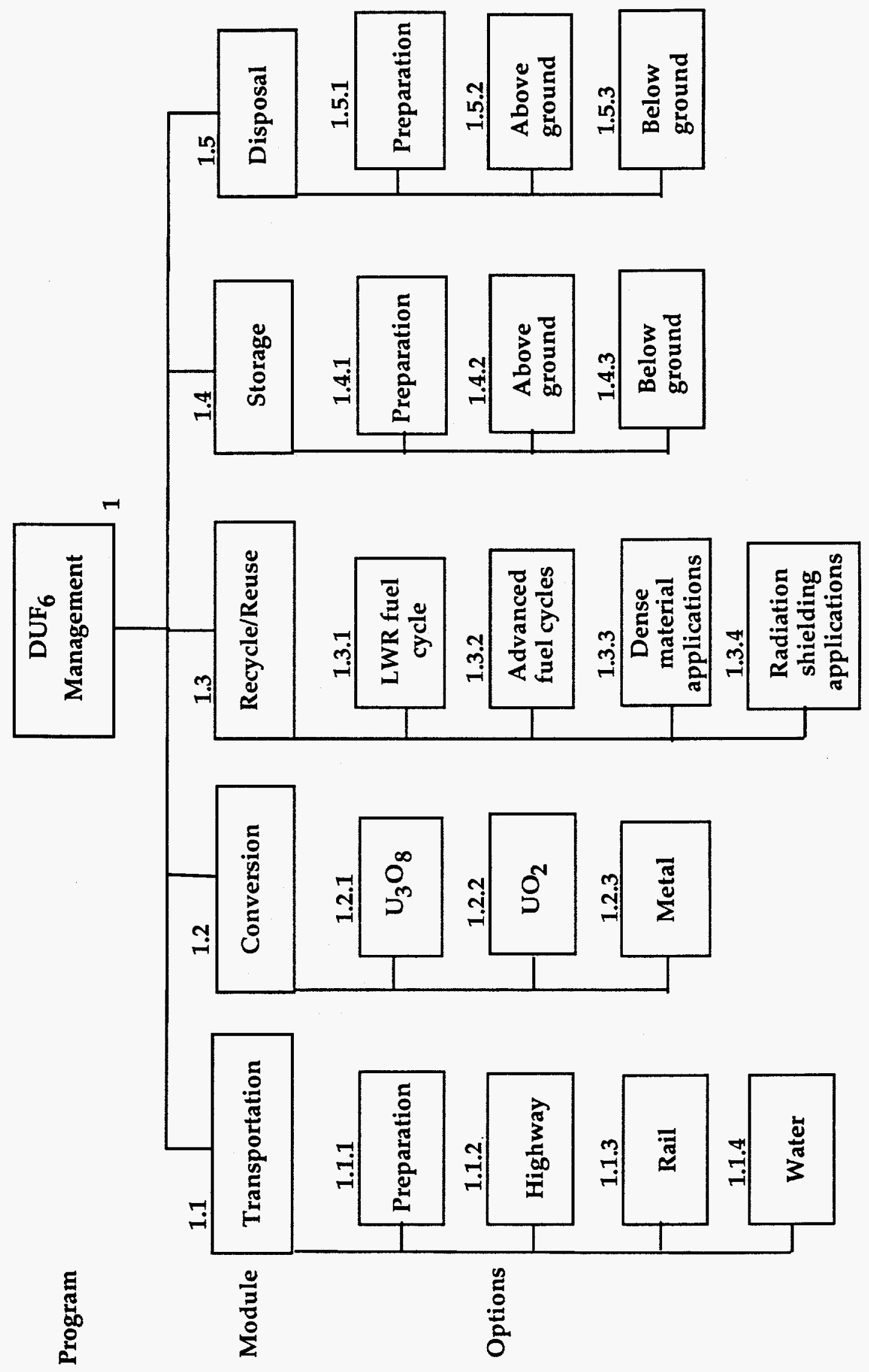

Figure 1. DUF 6 management WBS to Level III. 


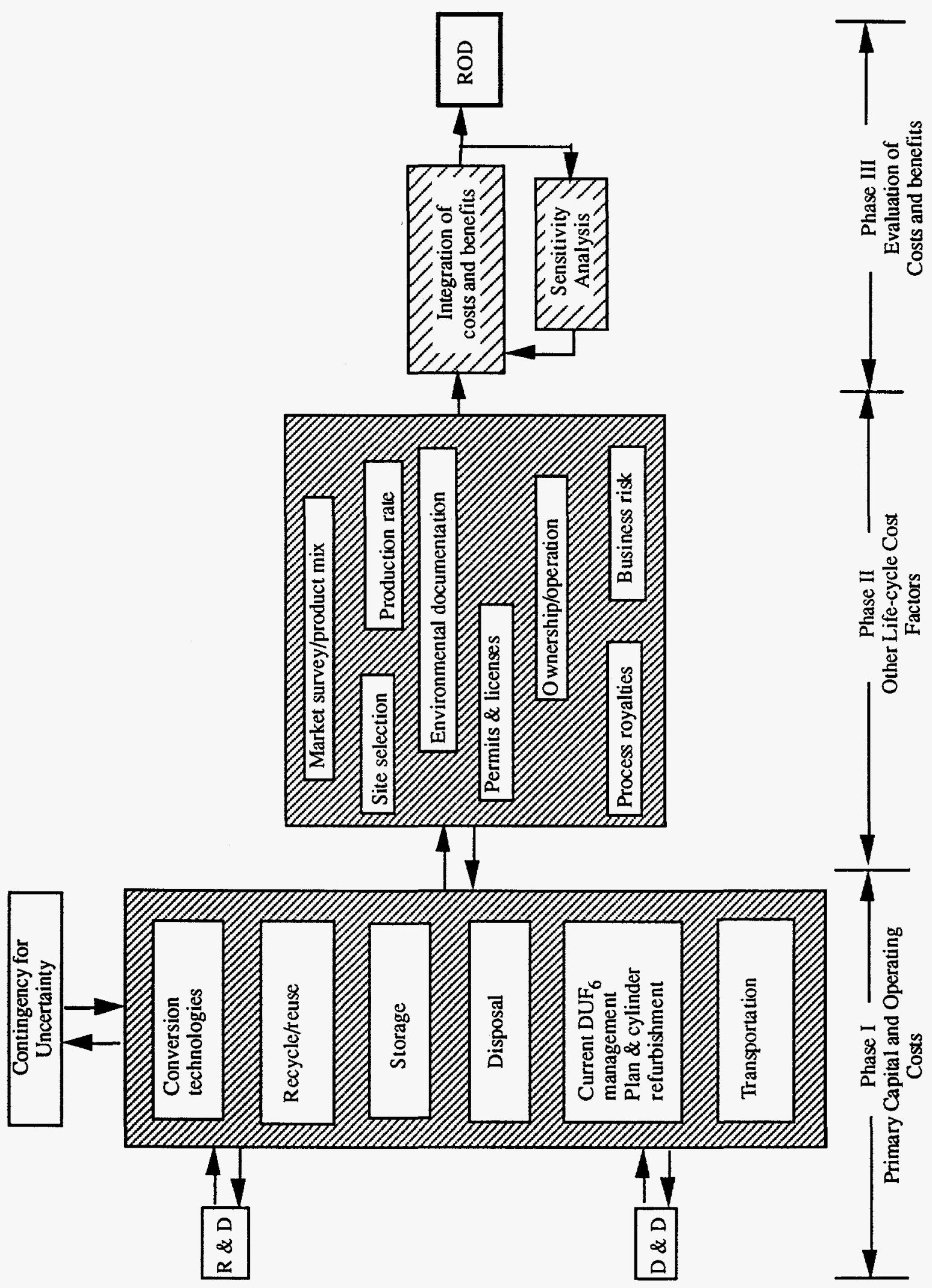

Figure 2. Cost Analysis Guidelines Scope. 


\section{Approach}

The costs will be addressed in a three-phase process. In Phase I, the costs of the primary contributors to capital and operating costs will be developed. In Phase II, factors for other lifecycle costs, will be analyzed. These two phases will be performed concurrently. In Phase III, the costs and revenues estimated in Phases I and II will be integrated into a cost model that can be used to evaluate the total life-cycle cost of a variety of long-term DUF6 management options. An analysis of the sensitivity of the results to different input values will be conducted to identify the variables that contribute the most to the net life-cycle cost.

The costs will be analyzed in accordance with Office of Management and Budget (OMB) and DOE guidelines on capital and operating cost analyses. The OMB circular deals mainly with discounting and escalation procedures and rates. The DOE guidelines address comprehensively the approach to be used in estimating facility and operating costs including factoring.

\subsection{Phase I: Cost Estimation for Primary Capital and O/M Costs}

Each of the primary cost contributors, the major modules, is the subject of engineering analysis as part of the Engineering Analysis Project. Data required from the Engineering Analysis Project is described in the Data Requirements Report, which gives the general approach to developing conceptual components and costs for evaluation of DUF6 management strategy alternatives. Data useful to the cost analysis will be transmitted from the Engineering Analysis Project to the Cost Analysis Project via the engineering data input reports and a series of addenda to the input reports known as Cost Estimate Data supplements. An addendum for each of the major technologies will be prepared that describes engineering quantities and other information necessary for the cost analysis.

The costs will be developed in accordance with a cost breakdown structure (CBS) paralleling the work breakdown structure (WBS) used in the Engineering Analysis Project. This cost breakdown structure provides flexibility to analyze a variety of combinations of modules that comprise a management strategy. For example, as shown on Fig. 1, there are five modules or basic building blocks for construction of a complete DUF6 management strategy: Transportation, conversion, recycle/reuse, storage, and disposal. Under these are various options (WBS/CBS Level III). Figure 3 shows an example of the work breakdown to Level VI for conversion. Level IV describes a specific suboption; Level V contains seven elements common to the Options: technology development, process equipment, process facilities, balance of plant, regulatory compliance, operation and maintenance, and decontamination and decommissioning. Under these, in Level VI, are subcomponents such as materials, utilities, labor, and waste management and disposal for operations and maintenance. Costs will be developed at one level below that at which they are reported, in this case, in a Level VII, which will be used to collect the cost data and estimates reported at Level VI or V.

\subsection{Phase II: Other Life-Cycle Cost Factors}

Other life-cycle costs will be the subject of their own special studies. Examples of these include ownership and operation; market survey; permits, licensing, and environmental documentation; and site selection. Most of the studies of the other life-cycle costs involve an initial data collection and analysis process. The preliminary results will be introduced into the cost model to determine whether they impact total cost by $5 \%$ or more. If the impact is greater than $5 \%$, then preliminary results will be reviewed and verified and the initial values adjusted to reflect more current or detailed information and analysis. Examples are projected sales and revenue in the 


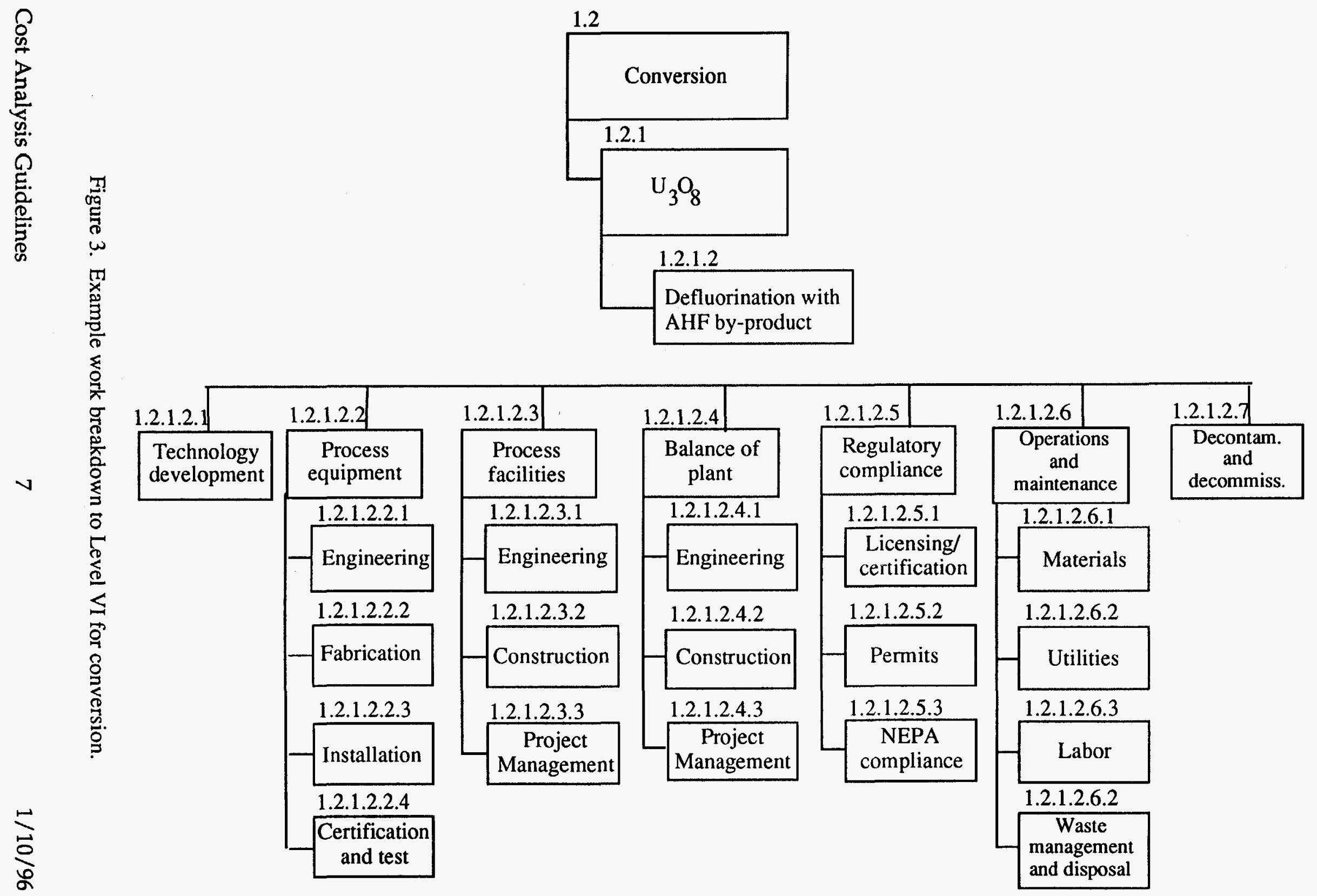


marketing study, the site or sites chosen for the facilities, ownership and operation, assessment, transportation and business risk contingency, and permits and licensing.

The cost model will be designed to accommodate different levels of production throughput. The baseline is 28,000 Tons DUF6/yr, assuming 20 years of operation to process 560,000 Tons of DUF6. Capital and operating costs do not scale linearly with throughput. The cost analysis will provide a reasonable representation of the nonlinear relationship between production and cost. The decision whether or not to analyze different levels of production throughout is expected to be deferred until after scoping.

\subsection{Phase III: Integration of Costs}

A computer model will be developed to integrate the primary capital and operating costs and other supporting costs and factors. The model will use the production capacity to specify the equipment and facilities requirements, operating and maintenance requirements, and costs for facilities within the range of production capacities considered in the Engineering Analysis. Unit costs and facility size will be used as a base, to which will be added appropriate costs for installation, project management, taxes, contingency, and other factors, site preparation and utility costs, and decommissioning, decontamination, demolition, disposal, and site restoration costs. The model will produce a series of cost estimates for each alternative that are displayed in tabular and graphic form. The model will enable analysts to study many different alternatives and variants and building them up from "modules" of activity. A sensitivity analysis of key parameters, such as size/throughput of conversion or manufacturing plant; product/strategy mix; escalation, discount, and interest rates; cost risk (contingency) factors; and transportation distances that may affect the ultimate cost of alternatives will be performed.

This section will describe the other parameters that are necessary in determining the ultimate cost of the various alternatives. Examples include:

- Sales revenues

- $\mathrm{R} \& \mathrm{D}$ costs

- D \& D cost basis

- Sites and locations

- Ownership/operation parameters (cost of money, discount rate)

- Product/waste mix

- Production throughput level evaluation (3 levels)

- Process royalty costs 



\section{Life-Cycle Cost Estimates}

The capital and operating cost will be developed and reported year by year over the life of the project in accordance with the project schedule. In effect, a cash flow analysis will be prepared to establish Life-Cycle Costs. All costs will be reported in first quarter FY96 dollars. The effects of inflation and the time value of money will be considered in Phase III of the analysis. The following schedule elements will be used in generating all cost estimates. Schedule estimates from the engineering data input reports will be used. The time until startup and the time for D\&D may vary by option. D\&D will be begin at the end of 20 years of conversion or manufacturing, and later for storage and disposal facilities. All such variances will be noted and scrutinized.
$\mathrm{R}$ \& $\mathrm{D}$, permitting, licensing, environmental documentation, design, construction, post-construction startup
Operations
$10 \mathrm{yr}$.
D \& D
$20 \mathrm{yr}$.
$3 \mathrm{yr}$.

The costs developed in Phases I and II will be developed according to the categories listed Table 1. These are similar to federal government budgetary categories. The first column of the table shows the appropriate phase of the cost analysis. The second column is the category number and the third column is a short category descriptor. More complete descriptions and guidelines are below, with each category number corresponding to a subsection number.

In general, a scoping-level combination of vendor quotes, a factored approach based on historical cost data, and a detailed engineering (bottoms-up) approach will be used in estimating costs. A factored approach is used when historic data are available for cost elements, for example, for the cost per sq. ft. of a particular kind of building. The total cost is estimated using the structure size and the per square foot cost factor. A detailed engineering approach begins with a specific facility design, and from this, estimates are made of the quantities of materials, labor, and other components required. Unit costs are applied to these estimated quantities to prepare the direct cost estimates. Additional costs are estimated using assumptions concerning the type of construction, safety and environmental regulations, production throughput, and other factors.

\subsection{R\&D}

Research and Development (R\&D) Costs will be based on the same cost items as outlined under Capital Costs (Categories 7-12). Existing site facilities, process systems, equipment, etc., that are used for R\&D must meet DOE $6430.1 \mathrm{~A}$ and other regulatory requirements as stated in the data input reports. Allowance will be made for all cost item upgrades. Process wastes and disposal and other life cycle costs will be determined separately and be accounted for in total costs.

\subsection{NEPA, Permitting, Licensing}

Scoping-level estimates will be developed of the cost of permitting, licensing, and environmental documentation under public, and private ownership and operation. This cost covers preparation of the site-specific EIS (which follows the more generic PEIS), NRC licenses, and state, local, and federal permits related to air and water quality. Construction permits are also included in this category. 
Table 1.

\begin{tabular}{|c|c|c|}
\hline Phase & $\begin{array}{l}\text { Category } \\
\text { Number }\end{array}$ & Category Title \\
\hline & & PREOPERATIONAL COSTS: \\
\hline $\mathrm{I}$ & 1 & R\&D \\
\hline$\overline{I I}$ & 2 & $\begin{array}{l}\text { Permits, Licensing, and Environmental } \\
\text { Documentation }\end{array}$ \\
\hline $\mathrm{I}$ & 3 & Conceptual Design \\
\hline II & 4 & Site Qualification \\
\hline $\bar{I}$ & 5 & Start-up \\
\hline $\bar{I}$ & 6 & Site Selection \\
\hline & & CAPITAL: \\
\hline $\mathrm{I}$ & 7 & Title I,II,III Engineering, Design, \& Insp \\
\hline $\bar{I}$ & 8 & Direct \& Indirect Construction/Modification \\
\hline$\overline{\mathrm{I}}$ & 9 & Construction Management \\
\hline$\overline{\mathrm{I}}$ & 10 & Initial Spares (Technology dependent) \\
\hline$\overline{\mathrm{I}}$ & 11 & Miscellaneous \\
\hline $\mathrm{I}$ & 12 & Contingency \\
\hline & & OPERATIONS COSTS: \\
\hline $\bar{I}$ & 13 & Operations \& Maint. Staffing \\
\hline $\bar{I}$ & 14 & Consumables \\
\hline $\mathrm{I}$ & & Electric power \\
\hline$\overline{\mathrm{I}}$ & & Misc. purchased replaceable $\&$ parts \\
\hline$\overline{\mathrm{I}}$ & & Process chemicals \& feedstocks \\
\hline $\mathrm{I}$ & 15 & Major Capital Replacements or Upgrades \\
\hline $\mathrm{I}$ & 16 & Waste handling \& disposal \\
\hline $\bar{I}$ & & Sanitary Waste \\
\hline $\mathrm{I}$ & & Mixed waste \\
\hline $\mathrm{I}$ & & RCRA waste \\
\hline $\mathrm{I}$ & & Low level \\
\hline $\bar{I}$ & & Other \\
\hline II & 17 & Oversight/ownership \\
\hline II & 18 & Fees and royalties \\
\hline$\overline{\mathrm{II}}$ & 19 & Payments-in-lieu-of-taxes to local communities \\
\hline II & 20 & Revenues (if applicable) \\
\hline $\mathrm{I}$ & 21 & Gov't subsidies or fees to private-owned facility \\
\hline $\bar{I}$ & 22 & Transportation \\
\hline $\mathrm{I}$ & $\overline{23}$ & Storage \\
\hline & & OTHER LIFE CYCLE COSTS: \\
\hline $\bar{I}$ & 24 & $\mathrm{D} \& \mathrm{D}$ \\
\hline III & 25 & Cost of Capital \\
\hline
\end{tabular}


This category covers the legal and technical work needed to obtain the NRC license needed to begin construction. Some technical work, such as safety documentation, would be performed by vendors, new owners or National Laboratories. Costs of NRC staff for the various NRC reviews will be added. All costs for DOE reviews will be reported. Cost's for studies and documentation prepared by owners, vendors, labs, and M\&O Contractors, are expected to be the prevalent costs.

\subsection{Conceptual Design}

Design work performed prior to Title I design and funded out of the DOE operating or new owners budget, falls in this category. Usually this work is performed by an Architect/ Engineering firm or by the resident engineering staff at an Management \& Operations (M\&O) contractor site. Such a design is usually the first "bottoms-up" design using take-offs from drawings and equipment specs and includes a cost estimate.

\subsection{Site Qualification}

Once a site for a facility is recommended, it must be certified that the site geology, infrastructure, and meteorology is capable of safely accommodating the facility and any wastes or emissions generated therefrom. For geologic disposition options this can be a lengthy and expensive step. Much of the work includes environmental and geologic sampling and documentation of findings. Although no specific sites will be selected during this phase of the DUF6 Management Program, generic site qualification costs will be developed.

\subsection{Start-up (activities prior to normal operations)}

Prior to commencing normal operations, the operator of a facility (presumably an $\mathrm{M} \& \mathrm{O}$ contractor/owner) must become familiar with the facility processes. Technology and information transfer from vendors to the $\mathrm{M} \& \mathrm{O} /$ owner is required. DOE Orders and NRC Requirements also require extensive training of $\mathrm{M} \& \mathrm{O}$ staff not only on technical operations, but also the E,S,\&H aspects of facility operations.

Current regulatory regimes require complete documentation of operational procedures prior to facility startup. Manuals for various process equipment items must also be prepared as part of this activity. Both vendors and $\mathrm{M} \& \mathrm{O}$ contractors/owners may be involved.

The facility project office must prove to the NRC or DOE that the facility is ready to commence operations in a safe and environmentally benign manner. Considerable contractor and regulatory staff time may be required to prepare for and carry out these reviews.

\subsection{Site selection}

This category includes all costs associated with purchase of site, site related costs, i.e., power to site, etc. in preparation to start venture. Although no specific sites will be selected during this phase of the DUF6 Management Program, generic site selection costs will be developed.

\subsection{Engineering, Design, and Inspection}

Architect/engineering design fees will be estimated at $25 \%$ of total field cost. This includes Title I, II and III design and engineering.

Title I design is the first line-item funded design effort for a facility and includes detailed drawings, bills-of-material, and craft labor requirements. A Title I cost estimate is usually also produced. An architect/engineer firm is often used for this level of design effort. The design at 
this point will be site-specific. Title II design produces the final pre-construction drawings, billof-material, and other specifications. The same A/E firm as for Title I design is often used. Title III is engineering that takes place primarily during construction and involves verification that the Title II final design is being implemented. Inspection activities and Q/A are included in this category.

\subsection{Construction}

The initial site selection for costing purposes will be Kenosha, WI, a hypothetical greenfield site. This establishes basic manual labor rates, state sales tax for parametric analyses of various processes.

Davis-Bacon manual labor rates for Kenosha, WI, the Workers Compensation Insurance rates for Tennessee and a standard 40 hour work week will be used and an allowance for casual overtime. If costing involves existing or a different site, Davis-Bacon manual rates will be used for that specific area.

Direct construction costs include the cost of craft labor, construction materials (such as concrete forms, rebar, concrete, structural steel, piping, electrical raceway and cable, etc.), installed equipment (such as process equipment, and service equipment.

\section{Cost Element}

Site development:

Major equipment:

Process support equipment:

Process support systems:

Major facilities:

Support facilities:

Facility support systems:

State Sales tax on equipment:

\section{Basis, assumption, value range}

Greenfield, offsite utilities and services available; clearing, grading assumptions, etc.

Vendor quotes, historical data or a factor approach based on complexity, size, mass, and technical maturity

Same as major equipment or percentage of major equipment cost, depending on the type of support equipment

Actual cost or percent of major equipment cost, depending on the support system

Quantity takeoffs or "bottoms up" estimates or factored approach

$\$ / \mathrm{ft}^{2}$ or $\$ / \mathrm{cu} \mathrm{ft}$, depending on the classification of the facility

\$/unit or percent of total facility cost, depending on type of facility support system

$6 \%$ of equipment and materials, or depending on site or region assumed

Indirect costs are distributables (general conditions), overhead, and profit. These include support to direct construction for temporary construction facilities, construction equipment, construction support, field office expenses, and craft supervision. Construction facilities include on-site offices, warehouses, shops, change rooms, construction roads, construction parking lots, etc. Construction support includes construction tools and consumables, safety equipment, material handling and warehousing, general clean-up, etc. These costs will be estimated as: 
Distributables Field (General Conditions) costs

Contractors bond:

Contractor's overhead and profit:
$28 \%$ for materials and subcontracts and $75 \%$ for

labor of direct labor costs

$1 \%$ of Total contractors contract

$5 \%$ of materials and subcontract and $15 \%$ of labor

\subsection{Construction Management}

For Government owned facilities DOE usually hires a construction manager (normally an A/E firm) to handle the subcontracting of craft labor and to interact with the design A/Es and equipment vendors.
Construction management:
$10 \%$ of construction contract cost
Owners Management Cost:
$6 \%$ applied to total of above (if applicable)

\subsection{Initial Spares}

Initial spares are major and crucial extra equipment items purchased out of the project capital budget. These are items needed to ensure process operation in the event of the failure of a major piece of installed equipment. The nature and cost of these items is technology dependent.

Initial spare parts: $\quad 10 \%$ of total process equipment cost and $5 \%$ of support equipment cost

\subsection{Miscellaneous}

This cost item is for the identification and collection of any capital costs that may not fit in the above categories.

\subsection{Contingency on Capital Costs}

A contingency percentage for the preconceptual estimate will be used to account for the change to the labor and material/equipment items that are not specifically defined at the time the estimate is prepared. Since it is often experience-based, the unknown fraction is generally lower for a mature technology for which facilities have been built. It is generally assumed that the project scope (i.e. plant size, feedrate, base unit operations flowsheet, etc.) does not change and that the project stays on schedule.

Capital cost contingencies are of two general types. The first is for normal undefined direct and indirect costs that cannot be specifically defined at the preconceptual level of design and cost estimation. This contingency does not cover the cost effect of major schedule extensions or changes in project scope. This contingency is usually calculated as a percent $(5-50 \%)$ of direct plus indirect costs and is included in the capital cost.

The analysis of the standard contingency allowance will be performed for each major capital cost element. This analysis will include an assessment of the maturity of the design/process, the accuracy of the costs and the definition of process, process support equipment, and construction facilities elements. Contingencies are usually greater than $30 \%$ of direct plus indirect costs at preconceptual level of design.

The second type of contingency accounts for the potential cost of major factors beyond the control of the Architect/Engineer, Contractor, or Owner. Factors that adversely affect the project 
schedule or scope include additional $R$ \& $D$ required for new technologies and additional licensing, permitting, and environmental documentation.

\subsection{Operations and Maintenance Staffing}

\section{Direct Operations Staff}

This category includes salaries plus fringe benefits for those persons directly associated with operations, such a chemical operators, foremen, and technicians, plus their line supervision. Clerical and health physics support in the process area will be included here.

Number of shifts:

Breakdown of staffing \& cost/man-hour

Production rate

Plant availability:
One, two, or three depending on engineering design

Use site location labor rates include all benefits

Based on 20 years of operation, 28,000 Tons DUF6 per year

$80 \%$ of operating days / year unless engineering data reports specifically prescribe otherwise

\section{Direct Maintenance Staff}

This category includes salaries plus fringe benefits for those persons directly associated with maintenance.

Annual general facility maintenance:
$1 \%$ of all capital equipment cost plus $1 \%$ of facility cost of maintenance labor plus $\$ 25 /$ man-hour for consumables

\section{$\underline{\text { Indirect Staff }}$}

This category includes salaries plus fringe benefits for other personnel needed to run the facility in a safe and environmentally compliant manner meeting all Federal, state, and local regulations. Among the indirect staff would be medical personnel, cafeteria workers, accountants, Q/A clerks, engineers, R\&D staff (for post startup, process improvement R\&D), human resources personnel, firemen, stores clerks, travel clerks, in-house ES\&H oversight personnel, secretarial pool, etc. Some of these functions may be shared with other facilities on a DOE reservation and their costs allocated on a fair basis. Some of the data for these categories may be expressed as a ration against the number of direct staff.

\subsection{Consumables and Utilities}

All consumables and utilities will be estimated based on specific costs where possible. These include annuals costs for electric power, natural gas, fuel oil, water, purchased steam, phones, and other non-electric utilities. The cost of routine replacement items such as equipment parts, worker clothing, electronics, etc. will be included in this category. The annual cost of purchased electric power is to be included here. If power is provided by an onsite Government reactor, the value of the facility "house load" power will be noted. The unit cost of electricity will depend on location of the facility. Annual costs for also will be reported here.

Utilities and services cost:

Chemical or feed costs:
Actual charge per kwh, water usage from engineering analysis; or use of factors

Actual costs 


\subsection{Major Capital Replacements and or Upgrades}

Major items included in the capital estimate sometimes require replacement on a non-routine basis.

Major capital replacement: $\quad 2 \%$ of capital equipment annually

\subsection{Waste Handling and Disposal}

Depending on characterization of wastes by engineering studies, the cost of disposal will be determined by the approaches defined below. In addition, packaging and transportation costs will be added where applicable. Disposal costs were based on Murray (1994).

\section{Mixed Waste}

Disposal cost of radiation mixed waste will be reported in this category. A cost of $\$ 100 /$ cubic foot will be used.

\section{$\underline{\text { RCRA }}$}

Disposal cost of these substances will be reported in this category. A cost of $\$ 20 /$ cubic foot will be used.

Low-level Radwaste

Waste of this type is sent to DOE sites or special burial sites covered under regional LLW compacts. The cost is typically levied on a $\$ /$ cubic foot basis. A cost of $\$ 100 /$ cubic foot will be used.

\section{Sanitary Waste}

Facilities for disposal of sanitary waste are assumed to be on-site. The cost of sanitary waste disposal facilities will be included in the capital and operations costs.

\subsection{Oversight}

If the NRC (or another regulator), requires reimbursement for their services such as inspections, these costs will be reported here. If state and local regulators are to be reimbursed for their services such as inspections, these costs will be reported here.

\subsection{Fees and Royalties}

Most DOE-owned facilities are operated by an M\&O (Management and Operations) contractor on an award or fixed fee basis. A fee of $2 \%$ of annual reimbursed operating costs per year will be used. Any royalties to third parties for use of technology will also be reported here.

\subsection{Payments to Local Communities and Counties in Lieu of Property Taxes}

Payments to local communities and counties in lieu of property taxes (PILT) is paid at some DOE sites to make up for the fact that DOE facilities do not pay property taxes. At the same time however, DOE facilities and their employees have significant impact on the need for schools, roads, etc. Presently, DOE does not have a formula for PILT. In the future PILT may be needed to assure public acceptance of facilities. A PILT of one-half the M\&O contractor fee will be used. 


\subsection{Revenues}

All revenues sources will be entered. Some of the conversion processes result in marketable byproducts, such as the hydrofluoric acid (aqueous or anhydrous) produced in the defluorination process and calcium fluoride from the neutralization process. The recycle/reuse module anticipates direct use of the depleted uranium in some form. These products/byproducts will either generate revenue offsetting the costs or at least reduce or eliminate the cost of long-term storage and/or permanent disposal.

An initial market survey will be conducted to determine the size of markets for the major byproducts of the various conversion processes and products prepared for the Recycle/reuse alternatives. This will assist an initial product/waste mix determination. Prior to integrating the costs into the cost model, the findings in the initial market survey will be verified. Issues to be addressed include the annual sales of product, price, growth or reduction forecast for the markets, and an estimate of the capacity of the market to absorb additional supply without undue effect on price will be reviewed.

\subsection{Government-Paid Subsidies or Fees to Privately-Owned Facilities}

If a facility is privately owned, the Government's payments or subsidy may not be made until the facility is operating. This cost must recover the owner's life cycle costs plus the investors returns minus any sales revenues to the owner.

Although the engineering and cost analyses are being conducted at a level of detail just above specification of a specific commercial process, some of the conversion technology options may ultimately result in selection of processes protected by patents and subject to royalty payments. These will be reviewed and a submodel will be created to represent these potential costs.

\subsection{Transportation}

All costs of transportation of $\mathrm{DUF}_{6}$ will be tabulated. Under Phase I, an engineering cost analysis of transportation alternatives will be conducted and a submodel will be developed to assess the cost per unit quantity per unit distance, including allowance for any special transport container systems, vehicles, and site facilities that may be required. In Phase II, the cost implications of siting alternatives will be evaluated and the tradeoffs between transportation costs and economies of scale realized with one facility compared with multiple small facilities will be analyzed.

\subsection{Storage of DUF6}

Costs for temporary storage of uranium material in process will be determined. All costs associated with storage facilities will be based on exactly same cost estimates as outlined under capital costs (categories 7-12).

\subsection{Decontamination and Decontamination (D\&D)}

It will be assumed that a DOE $\mathrm{M} \& \mathrm{O}$ Contractor and perhaps an $\mathrm{A} / \mathrm{E}$ will shutdown, decontaminate, and remove contaminated and junk equipment from the facility. The cleaned out facility does not have to be demolished if it does not pose a radiation hazard. The D\&D cost will include disposal of contaminated or junked equipment to licensed disposal sites.

Decommissioning, and decontamination $10 \%$ of total facility costs or recent experience 
This is based on historic and projected D \& D costs for facilities of similar complexity, size, and hazardous waste characteristics.

\subsection{Cost of Capital}

There are three general alternatives for ownership and/or operation of the conversion, manufacturing, long-term storage, permanent disposal, and even transportation equipment and facilities. These are government, quasipublic (analogous to a utility company), and private organization. Each of these has implications for cost arising from the different capital organization, sources and cost of borrowing money, permitting and licensing requirements, ability to adhere to project schedule, operating requirements, and other factors. For example, if the government owns the facility, the primary financial parameter is the discount rate. The discount to be used is $5 \%$ for government capital and operating costs and $8 \%$ for a quasipublic (utility) entity in accordance with the OMB circular A-94.

The risks involved in commercial investment may affect the management of DUF6 depending on the ownership and operation of alternatives selected. This risk is often addressed by the use of different risk factors called beta factors, in constructing the internal target rate of return so-called a hurdle rate, used to evaluate competing investments in which a firm can allocate its resources. A similar approach will be used to represent the different business risks that the various conversion and manufacturing technologies entail for the private and quasi-private sectors. 


\section{References}

Dubrin, J., Work Breakdown Structure (Initial Report), Engineering Analysis Project, Depleted Uranium Hexafluoride Management Program, Lawrence Livermore National Laboratory, Livermore, CA (March 8, 1995)

Dubrin, J., Characterization of Options for the Depleted Uranium Hexafluoride Management Program (Initial Report), Engineering Analysis Project, Depleted Uranium Hexafluoride Management Program, Lawrence Livermore National Laboratory, Livermore, CA (February 24, 1995)

Lawrence Livermore National Laboratory, Engineering Analysis Project: Work Breakdown Structure (Initial Report) (Report number), Engineering Analysis Project, Uranium Programs Support Project, Lawrence Livermore National Laboratory, FESSP Washington Operations (March 8, 1995).

Murray, Alex, et al. Draft Summary Report on Applicability of the Minimum Additive Waste Stabilization (MAWS) Approach to Hanford Waste Streams, Science Applications International Corp. (September 20, 1994).

Office of Management and Budget, Circular A-95. 



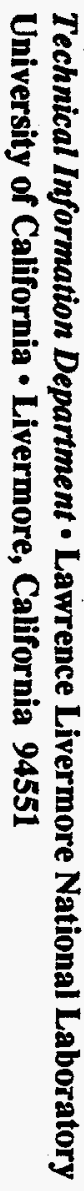

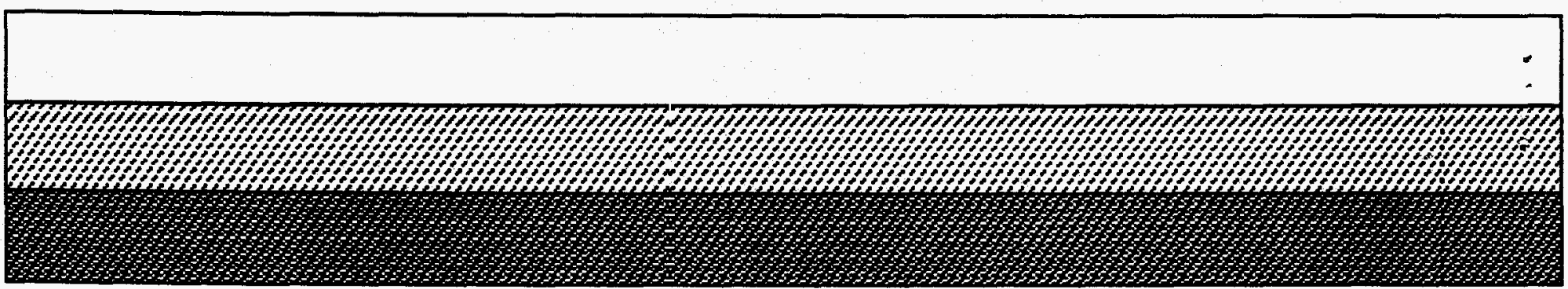

